\title{
BIOTRANSFORMATION OF ENT-BEYERENES WITH MUCOR PLUMBEUS
}

\section{MARÍA CRISTINA CHAMY', SILVIA OREJARENA², JUANA ROVIROSA² AND AURELIO SAN MARTIN*2,3}

\author{
${ }^{\prime}$ Depto de Química, sede Viña del Mar, Universidad Andrés Bello \\ ${ }^{2}$ Depto de Química, Facultad de Ciencias, Universidad de Chile, \\ ${ }^{3}$ Facultad de Ciencias, Universidad de Magallanes \\ (Received: July 18, 2013 - Accepted: October 7, 2013)
}

\begin{abstract}
The microbiological transformation of ent-beyer-15-en-18-ol 1 and ent-beyer-15-en-19-ol 2, using Mucor plumbeus, resulted in hydroxylated products. After nine days of incubation, $15 \beta, 16 \beta$-epoxide-ent-beyeran-7 $\beta, 18$-diol 3, ent-beyer-15-en-7 $\beta, 19$-diol 4 and $15 \beta, 16 \beta$-epoxide-ent-beyeran-7 $\beta, 19$-diol 5 were isolated. The metabolites were identified by spectroscopic methods.
\end{abstract}

Key Words: Mucor plumbeus, microbiological transformation, diterpenes, ent-beyerenes.

\section{INTRODUCTION}

Biotransformation is today considered to be an economically competitive technology by synthetic organic chemists in search of new production routes for fine chemical, pharmaceutical and agrochemical compounds'. From the different transformations catalyzed by enzymatic systems, the selective hydroxylation of non-activated carbon atoms is particularly interesting, because this transformation is difficult to achieve by classical methods ${ }^{2,3}$ The introduction of hydroxyl groups in diterpenoids may enhance existing properties or lead to new biological activities. Microbial transformations have been used to introduce hydroxyl groups at positions remote from the functional group on diterpenoid molecules, such as stemodanes ${ }^{4}$, kaurenes $^{5}$, pimaranes ${ }^{6}$, among others. We had carried out the biotransformation of ent-beyerene derivatives with Giberella fujikuroi (analogue biosynthesis) concluding that the presence of a 18 hydroxyl in the molecule is inhibitory for the formation of the gibberellins ${ }^{7,8}$. Although several microbial hydroxylations on beyerane derivatives ${ }^{9-11}$ have been described, to the best of our knowledge, there are no reports about biotransformation of ent-beyer-15-ene with Mucor plumbeus. In this work we describe the isolation and structural elucidation of the xenobiotic biotransformation of ent-beyer-15-en-18-ol, 1 and ent-beyer-15-en-19-ol, 2 with M. plumbeus

\section{EXPERIMENTAL}

General procedures.- ${ }^{1} \mathrm{H}$ NMR spectra were recorded in $\mathrm{CDCl}_{\text {, }}$ solution at $400.13 \mathrm{MHz}$, and the ${ }^{13} \mathrm{C}$ NMR at $125.03 \mathrm{MHz}$ in a Bruker multidimensional spectrometer. Purification by HPLC was achieved using a silica gel column (Ultrasphere Si $5 \mathrm{~lm}, 10-250 \mathrm{~mm}$ ). Dry column chromatography was made on silica gel Merck $0.040-0.063 \mathrm{~mm}$.

Microorganism.-The fungal strain was M. plumbeus CMI 116688 was a gift from Prof. M. Fraga Universidad de La Laguna, Tenerife, Spain.

Incubation procedure.- The fungus $M$. plumbeus, was grown on shake culture at $25^{\circ} \mathrm{C}$ for two days in 80 conical flasks $(250 \mathrm{~mL})$, each containing $50 \mathrm{~mL}$ of sterile medium comprising $\left(\right.$ per dm $\left.\mathrm{dm}^{3}\right)$ glucose $(80 \mathrm{~g}), \mathrm{NH}_{4} \mathrm{NO}_{3}(0.48$ g), $\mathrm{KH}_{2} \mathrm{PO}_{4}(5 \mathrm{~g}), \mathrm{MgSO}_{4}(1 \mathrm{~g})$, and trace elements solution $(2 \mathrm{~mL})$. The trace elements solution contained (per $100 \mathrm{~mL}) \mathrm{Co}\left(\mathrm{NO}_{3}\right)_{2}(0.01 \mathrm{~g}), \mathrm{CuSO}_{4}(0.015$ g), $\mathrm{ZnSO}_{4}(0.16 \mathrm{~g}), \mathrm{MnSO}_{4}(0.01 \mathrm{~g}),\left(\mathrm{NH}_{4}\right)_{6} \mathrm{Mo}_{7} \mathrm{O}_{24}(0.01 \mathrm{~g})$. The substrate dissolved in EtOH (11-16 mL) and Tween 80 (three drops) was evenly distributed between the flasks and the incubation allowed to continue for a further 9 days. The broth was filtered and the culture filtrate extracted with EtOAc. The mycelium was treated with liquid nitrogen, crushed in a mortar and extracted with EtOAc. Both extracts were combined and separated into 'acidic' and 'neutral' fractions with aqueous $\mathrm{NaHCO}_{3}$.

Incubation of ent-beyer-15-en-18-ol, $\mathbf{1}$ : The substrate $\mathbf{1}(300 \mathrm{mg})$ in EtOH $(20 \mathrm{~mL})$ was distributed between 80 conical flasks. Its biotransformation gave in the neutral fraction, starting material $(130 \mathrm{mg})$ and $15 \beta, 16 \beta$ - epoxide-entbeyeran-7 $\beta, 18$-diol $3(20 \mathrm{mg})$ and 15 $\beta, 16 \beta$ - epoxide-ent-beyeran-7 $\beta, 19$-diol, 4 $(45 \mathrm{mg})$. Transformed products were not obtained in the acid fraction.

15 $\beta, 16 \beta$-epoxide-ent-beyeran-7 $\beta, 18$-diol, $3:{ }^{1} \mathrm{H}$ NMR $\left(400 \mathrm{MHz}, \mathrm{CDCl}_{3}\right)$ : $4.02(1 \mathrm{H}, \mathrm{t}, \mathrm{J}=3.0 \mathrm{~Hz}, \mathrm{H}-7), 3.6(1 \mathrm{H}, \mathrm{d}, \mathrm{J}=11.0 \mathrm{~Hz}, \mathrm{H}-18), 3.3(1 \mathrm{H}, \mathrm{d}, \mathrm{J}=3.0$ $\mathrm{Hz}, \mathrm{H}-15), 3.1(1 \mathrm{H}, \mathrm{d}, \mathrm{J}=3.0 \mathrm{~Hz}, \mathrm{H}-16), 2.9\left(1 \mathrm{H}, \mathrm{d}, \mathrm{J}=11.0 \mathrm{~Hz}, \mathrm{H}-18^{\prime}\right), 1.06$ (3
$\mathrm{H}, \mathrm{s}, \mathrm{Me}-17) 0.95$ (3H,s, Me -20), 0.75 (3 H, s, Me-19) ${ }^{13} \mathrm{C}$ NMR: see Table 1 Incubation of ent-beyer-15-en-19-ol, 2: The substrate $2(300 \mathrm{mg})$ in EtOH $(20 \mathrm{~mL})$ was distributed between 80 conical flasks. Its biotransformation gave in the neutral fraction, starting material $(130 \mathrm{mg})$, ent-beyer-15-en-7 $\beta, 19$-diol 4 $\left(40 \mathrm{mg}\right.$ ) and $15 \beta, 16 \beta$ - epoxide-ent-beyeran- $7 \beta, 19$ - diol (5) $(50 \mathrm{mg}) .{ }^{13} \mathrm{C}$ NMR: see Table 1

Table 1. ${ }^{13} \mathrm{C}$ NMR data of Compounds $1-5\left(\mathrm{CDCl}_{3}, \mathrm{~d}\right.$ in ppm)

\begin{tabular}{|c|c|c|c|c|c|}
\hline Carbon $\mathbf{N}^{\mathbf{0}}$ & $\mathbf{1}^{*}$ & $\mathbf{2}^{*}$ & $\mathbf{3}$ & $\mathbf{4}$ & $\mathbf{5}$ \\
\hline 1 & 38.8 & 39.2 & 39.3 & 39.3 & 39.3 \\
\hline 2 & 18.0 & 18.3 & 18.2 & 18.5 & 18.1 \\
\hline 3 & 35.4 & 35.7 & 35.3 & 35.9 & 35.5 \\
\hline 4 & 37.6 & 38.5 & 37.6 & 38.2 & 37.5 \\
\hline 5 & 49.1 & 56.8 & 39.4 & 47.2 & 47.4 \\
\hline 6 & 19.9 & 20.1 & 27.3 & 27.9 & 27.7 \\
\hline 7 & 37.0 & 37.3 & 70.7 & 73.5 & 70.1 \\
\hline 8 & 48.6 & 49.0 & 49.6 & 54.6 & 49.2 \\
\hline 9 & 52.8 & 53.0 & 51.3 & 47.8 & 50.7 \\
\hline 10 & 37.1 & 37.3 & 37.2 & 37.5 & 37.9 \\
\hline 11 & 20.3 & 20.3 & 19.5 & 20.2 & 19.1 \\
\hline 12 & 33.3 & 33.2 & 35.3 & 33.1 & 35.0 \\
\hline 13 & 43.6 & 43.6 & 39.5 & 44.3 & 39.1 \\
\hline 14 & 61.2 & 61.2 & 42.5 & 56.8 & 42.3 \\
\hline 15 & 135.0 & 135.0 & 55.8 & 133.5 & 55.4 \\
\hline 16 & 136.0 & 136.5 & 60.0 & 136.5 & 59.7 \\
\hline 17 & 24.9 & 24.9 & 21.7 & 25.1 & 21.5 \\
\hline 18 & 72.3 & 27 & 71.2 & 27.0 & 26.7 \\
\hline 19 & 17.7 & 65.5 & 18.0 & 66.1 & 65.7 \\
\hline 20 & 15.6 & 15.6 & 15.9 & 15.5 & 15.8 \\
\hline & & & & & \\
\hline
\end{tabular}

*Values in these columns were taken from the literature ${ }^{11}$

ent-beyer-15-en-7b,19-diol, 4: ${ }^{1} \mathrm{H}$ NMR $\left(400 \mathrm{MHz}, \mathrm{CDCl}_{3}\right): 5.53(1 \mathrm{H}, \mathrm{d}$ $\mathrm{J}=5.7 \mathrm{~Hz}, \mathrm{H}-15), 5.49(1 \mathrm{H}, \mathrm{d} \mathrm{J}=5.7 \mathrm{~Hz}, \mathrm{H}-16), 3.76(1 \mathrm{H}, \mathrm{d}, \mathrm{J}=10.9 \mathrm{~Hz}, \mathrm{H}-19)$, $3.68(1 \mathrm{H}, \mathrm{t} \mathrm{J}=2.7 \mathrm{~Hz}, \mathrm{H}-7), 3.45(1 \mathrm{H}, \mathrm{d}, \mathrm{J}=10.9 \mathrm{~Hz}, \mathrm{H}-19), 1.04$ (3 H, s, Me18), $0.98(3 \mathrm{H}, \mathrm{s}, \mathrm{Me}-\mathrm{H}), 0.73(3 \mathrm{H}, \mathrm{s}, \mathrm{Me}-20) \cdot{ }^{13} \mathrm{C}$ NMR: see Table 1

15 $\beta, 16 \beta$-epoxide-ent-beyeran-7 $\beta, 19$-diol, 5: ${ }^{1} \mathrm{H}$ NMR $\left(400 \mathrm{MHz}, \mathrm{CDCl}_{3}\right)$ : $3.99(1 \mathrm{H}, \mathrm{bt}, \mathrm{J}=2.6 \mathrm{~Hz}, \mathrm{H}-7), 3.77(1 \mathrm{H}, \mathrm{d}, \mathrm{J}=11 \mathrm{~Hz}, \mathrm{H}-19), 3.48(1 \mathrm{H}, \mathrm{d}, \mathrm{J}=11$ Hz, H-19'), 3.30 (1H, d, J=2.9 Hz, H-15), 3.07 (1H,d, J=2.9 Hz, H-16), 1.06 
(3H, s, Me-17), 0.99 (3H, s, Me-18), 0.91 (3H, s, Me-20), 1.23 (1H, dd, J=2.8 and $10.8 \mathrm{~Hz}, \mathrm{H}-14) 0.79(1 \mathrm{H}, \mathrm{d}, \mathrm{J}=10.8 \mathrm{~Hz} \mathrm{H}-14) \cdot{ }^{13} \mathrm{C}$ NMR: see Table 1<smiles>CC12C=C[C@]3(CCC4C(C)(C)CCC[C@]4(C)C3CC1)C2</smiles>

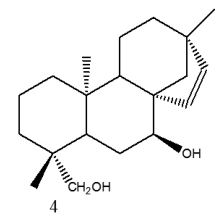<smiles>CC12CC[C@@]34CCCC(C)(C)[C@@H]3CC[C@@]4(CC1)C2</smiles><smiles>CC12CCC3[C@](C)(C1)C1O[C@H]1[C@]3(C)CCC[C@@]2(C)CO</smiles>

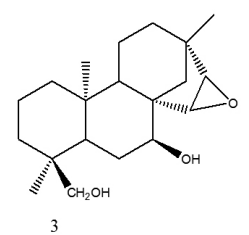

Figure 1: Natural and Biotransformed terpenes.

\section{RESULTS AND DISCUSSION}

Baccharis tola (Compositae), popularly known as "ñaka or lejía" is a perennial herb that grows wild in Antofagasta, Chile. Previous phytochemical studies of these plant established the presence of the triterpene oleanolic acid, as well as two ent-beyerene -type diterpenoids, ent-beyer-15-en-18-ol, $\mathbf{1}$ and ent-beyer-15-en-19-ol, 2. These diterpenoids are rare and little-studied biologically thus far ${ }^{11}$.

Each substrates were added to 36 hours-old shake cultures of M. plumbeus and the metabolites were extracted after a further 9 days, combined broth and mycelium extract were chromatographed eluting with mixtures of petroleum ether-EtOAc of increasing polarity. The fermentation of ent-beyer-15-en-18-ol, 1 afforded compound 3, and the fermentation of ent-beyer-15-en-19-ol, 2 gave compounds $\mathbf{4}$ and $\mathbf{5}$. The ${ }^{1} \mathrm{H}$ NMR spectrum of $\mathbf{3}$ was very similar to that of $\mathbf{1}$ with the disappearance of the olefinic protons in $\mathbf{1}$ at $\Delta 5.60$ and $5.43(\mathrm{~d}, \mathrm{~J}=6 \mathrm{~Hz}$, $1 \mathrm{H}$ each) and the appearance of two doublets at $\Delta 3.3$ and $3.1(1 \mathrm{H}$ each, $\mathrm{d}, \mathrm{J}=3.0$ $\mathrm{Hz}$ ) corresponding to the protons of an oxirane ring and a broad triplet at $\Delta 4.02$ corresponding to a methine proton bearing an hydroxyl group. The position of the newly introduce hydroxyl (C-7) was established by unambiguous assignments of all carbons and protons through combined use of HMQC, HMBC and COSY 45 spectra. The HMBC spectrum of $\mathbf{3}$ showed correlation of H-7 (d 4.02 brt) with C-5 (d 39.4) and C-9 (d 51.3). The $\Delta$ stereochemistry of the hydroxyl group al C-7 was established by the pattern of H-7 $\Delta 4.02$ $(\mathrm{t}, \mathrm{J}=3 \mathrm{~Hz}$ ). Furthermore, Me-17 was shifted from $\Delta 0.77$ in $\mathbf{1}$ to $\Delta 1.06$ in $\mathbf{3}$ indicating that the oxirane ring must be between $\mathrm{C}-15$ and $\mathrm{C}-16$ and confirmed by the HMBC spectrum, which showed correlations between Me-17 ( $\Delta$ 1.06) and $\mathrm{C}-16(\Delta 60.0), \mathrm{C}-12(\mathrm{~d} 35.3)$ and $\mathrm{C}-14(\mathrm{~d} 42.5)$. It is of interest to note that in the ${ }^{13} \mathrm{C}$ NMR spectrum of this compound, the pronounced shielding effect exerted by the 15,16 epoxide on $\mathrm{C}-14 .\left(\Delta \mathrm{d}_{1-3}-18.7\right)$. The $\left(\mathrm{CH}_{2}\right)_{14}$ signal appears as a doublet doublet instead of a triplet in the spectrum of $\mathbf{1}$ indicating the $\beta$ orientation of the epoxide ring $^{12}$. So, compound 3 must be $15 \beta, 16 \beta$-epoxideent-beyeran-7 $\Delta, 18$-diol. The fermentation of ent-beyer-15-en-19-ol, 2, gave compounds 4 and 5 see Figure 1.

The ${ }^{1} \mathrm{H}$ NMR spectrum of $\mathbf{4}$ was very similar to that of $\mathbf{1}$. The ${ }^{1} \mathrm{H}$ NMR spectrum of $\mathbf{4}$ shows methyl signals at $\Delta 1.04,0.98$ and 0.73 , a collapsed $\mathrm{AB}$ system at $\Delta 5.50$ assigned to a $Z$ olefin with no hydrogens at the vicinal carbon atoms, a $\mathrm{Q}_{\mathrm{AB}}$ systems with $J=10.9 \mathrm{~Hz}$ and signals centered at $\Delta 3.76$ and 3.45 attributable to the $-\mathrm{CH}_{2} \mathrm{OH}$ group situated at $\mathrm{C}-19$. A signal at $\Delta 3.68(\mathrm{bt}, \mathrm{J}=2.7$ $\mathrm{Hz}$ ) attributable proton geminal to an hydroxyl group. The chemical shift and form of the signal of this proton described may be due to an equatorial proton geminal to the hydroxyl group. The position of these newly introduce hydroxyl (C-7) was confirmed by ${ }^{13} \mathrm{C}$ NMR spectrum (Table 1 ). The signal for $\mathrm{C}-5$ was shifted upfield by $\Delta \mathrm{d}_{1-4} 9.6 \mathrm{ppm}, \mathrm{C}-9, \mathrm{C}-14$ and C-15 were shifted upfield by $\Delta \mathrm{d}_{1-3} 5.2,4.4$ and 1.5 respectively and C-6 and C-8 were shifted downfield by $\Delta \mathrm{d}_{1-4} 7.8$ and $5.6 \mathrm{ppm}$. Therefore, compound 4 must be ent-beyer-15-en-7 b, 19-diol.

The ${ }^{1} \mathrm{H}$ NMR spectrum of compound $\mathbf{5}$ is very similar to that of $\mathbf{3}$. The only differences are the signals corresponding to the hydroxymethylene which are shifted from $\Delta_{H} 3.6$ and 2.9 in $\mathbf{3}$ to $\Delta 3.77$ and $3.48(1 \mathrm{H}$ each, $\mathrm{d}, \mathrm{J}=11.0 \mathrm{~Hz})$ and $\Delta_{C}$ from 71.2 to $66.1 \mathrm{ppm}$ in $\mathbf{5}$ which is indicative of the hydroxyl in C-19. So compound 5 must be $15 \beta, 16 \beta$ - epoxide-ent-beyeran-7 $\Delta$,19-diol.

\section{CONCLUSIONS}

The presence of an hydroxyl group at C-18 or C-19 does not affect the hydroxylation pattern with $M$. plumbeus. A different situation was observed in the biotransformation of these products with G. fujikuroi, where only compound $\mathbf{2}$ produced gibberellines and compound $\mathbf{1}$ produced hydroxylation at $\mathrm{C}-7$ and $\mathrm{C}-19^{7}$.

\section{ACKNOWLEDGEMENTS}

This work was supported by Grant No 1120199 from FONDECYT

\section{REFERENCES}

1. B.G. Davis, V. Boyer, Nat. Prod. Rep. 18, 618 (2001).

2. L.R. Lehman, J.D. Stewart, Curr. Org. Chem. 5, 439 (2001).

3. J.R. Hanson, Nat. Prod. Rep. 9, 139 (1992).

4. B. M. Fraga, R. Guillermo, M. G. Hernández, M. C. Chamy, J. Garbarino, Tetrahedron, 60, 7921 (2004).

5. S. Marquina, J. L. Parra, M. González, A. Zamilpa, J. Escalante, M. R. Trejo-Hernández, L. Álvarez, Phytochem. 70, 2017 (2009).

6. B.M.Fraga, P.Gonzalez, M.G.Hernandez, M.C.Chamy, J.A.Garbarino, Phytochem. 47, 211 (1998)

7. C.E. Díaz, B.M. Fraga, A.G. Gonzalez, J.R. Hanson, M.G. Hernández, A. San-Martín, Phytochem. 24, 1489 (1985).

8. A. San-Martín, J. Rovirosa, M. Castillo, Phytochem. 22, 1461 (1983).

9. H.S. Ali, J.R. Hanson, B.H. de Oliveira, Phytochem. 31, 507 (1992).

10. A. García-Granados, A. Parra, J.M. Arias, J. Nat. Prod. 60, 86 (1997).

11. A. García-Granados, A. Guerrero, A. Martínez, A. Parra, J.M. Arias, Phytochem. 36, 657 (1994).

12. A. San-Martin, J. Rovirosa, R. Becker, M. Castillo, Phytochem. 19, 1985 (1980). 